\title{
Intertwining Perspectives and Negotiation
}

\begin{abstract}
Cooperative work typically involves both individual and group activities. Computer support for perspectives allows people to view and work in a central information repository within personal contexts. However, work in personal perspectives encourages divergent thinking. Negotiation in group perspectives is needed to converge on consensus, shared understanding, and cooperation. Negotiation processes on their own can delay progress. By intertwining perspective and negotiation mechanisms, individual results can be systematically merged into a group product while work continues. Personal perspectives on shared information are thereby intertwined and merged into a shared group understanding. WebGuide is a prototype system that integrates perspective and negotiation mechanisms; its user interface has been mocked up in detail to work out the many issues involved. We have begun to use partial implementations of WebGuide to support cooperative intellectual work in small research groups.
\end{abstract}

\section{SUPPORT FOR INDIVIDUAL AND GROUP PERSPECTIVES}

The World Wide Web (the Web) provides an obvious medium for cooperative work. However, it provides no support for the interplay of individual and group understanding that drives collaboration. First, we need ways to find and work with information that matches our needs, interests, and capabilities. Then we need means for bringing our 
individual knowledge together to build a shared understanding and cooperative products.

In this paper, we explore the possibility of providing computer support for intertwining perspectives in cooperative work by means of an integrated system of perspective and negotiation mechanisms.

Our approach combines previous research we conducted individually on computer support for perspectives [23] and for negotiation $[10,11]$. The term perspective means that a particular, restricted segment of an information repository is being considered, stored, categorized, and annotated. Computer support for perspectives allows people in a group to interact with a shared, global information source; everyone views and maintains their own perspective on the information without interfering with content displayed in the perspectives of other group members. The problem is that perspectives of group members tend to diverge instead of converging as work proceeds.

Computer support for negotiation provides a solution to the divergence of ideas in different perspectives by allowing members of a group to communicate about what information to include as mutually acceptable. The problem with negotiation is that it delays work on information while potentially lengthy negotiations are underway. Here, perspectives provide a solution, allowing work to continue within personal perspectives while the contents of shared perspectives are being negotiated.

We believe that perspectives and negotiation are each important CSCW concepts in their own right, but that when combined they can offset each other's major weaknesses and provide powerful support for using shared information sources. We propose an approach to intertwining the mechanisms of perspectives and negotiation to help cooperative groups intertwine the personal perspectives of their members into an effective shared network of perspectives on taskrelevant information. Our proposal is based on the normative standpoint that even in the case of distant and asynchronous cooperation people should have a chance to contribute to the convergence of their ideas.

The first section of this paper characterizes perspective and negotiation mechanisms that the authors developed independently in the past, followed by a section on related work to differentiate our approach from others. $\mathrm{CSCW}$ approaches often deal with the problem 
of joint editing of a shared document by several users and the subsequent merging of different versions. By contrast, in our approach many short segments (from selected and inherited individual perspectives) are dynamically extracted from a shared information source and intertwined to construct personal and team perspectives.

The paper's third section describes a student research project that helped us to define the requirements for computer support of this kind of cooperative work. This motivated the design of WebGuide, a prototype system that is then described in some detail. The paper concludes with current work - introducing our software into classrooms and small research groups for testing its use - and future work to evaluate its effectiveness.

\section{PREVIOUS WORK ON PERSPECTIVES AND NEGOTIATION}

This paper integrates twio previously independent approaches: collaboration using perspectives and negotiation of shared information.

\section{Perspectives}

The most important characteristics of Stahl's [23] perspective mechanism are:

- Individual team members have access to what appears to be their own information source. This is called their personal perspective. It consists of items from a shared central information repository that are tagged as being visible within that particular perspective (or in any perspective inherited by that perspective).

- Team member A can integrate an item from B's perspective into her personal perspective by creating a virtual copy of the item. If B modifies the original item, then it changes in A's perspective as well. However, if A modifies the item, a new item is actually created for A, so that B's perspective is not changed. This arrangement generally makes sense because A wants to view (or inherit) B's item, even if it evolves. 
However, B should not be affected by the actions of someone who copied one of B's items.

- Alternatively, team member A can physically copy the contents of an item from B's perspective. In this case, the copies are not linked to each other in any way. Since A and $\mathrm{B}$ are viewing physically distinct items now, either can make changes without affecting the other's perspective.

- When A creates a virtual copy of an item from B's perspective, A can decide if she will also get virtual copies of items related to that one, or if she will create her own subnetwork for her copy of that item. Arbitrarily large subnetworks of information can be inherited with no overhead in time or memory using the virtual copy mechanism.

- Items of information can be created, edited, or deleted by users within their own personal perspective without affecting the work of others.

- New perspectives can be created by users. Perspectives can inherit from existing perspectives. Thus, a team perspective can be created that includes virtual copies of all contents of the inherited perspectives of the team members. There is an inheritance tree of perspectives; descendants inherit the contents of their ancestor perspectives. Changes (additions, edits, deletions) in the ancestor are seen in descendent perspectives, but not vice versa. A hierarchy of team, subteam, and individual perspectives can be built to match the needs of a particular application.

This model of perspectives has the important advantage of letting team members copy the content of their team's perspective and other information sources without having to generate it from scratch. They can then experiment with this content on their own without worrying about affecting what others see. This is advantageous as long as one only wants to use someone else's information to develop one's own perspective. It has frequently been noted in computer science literature $[5,8]$ that different stakeholders engaged in the development and use of a system (e.g., designers, testers, marketing, management, end-users) always think about and judge issues from different perspectives and that these differences must be taken into account.

However, if one wants to influence the content of other team members' perspectives, then this approach is limited because one 
cannot change someone else's content directly. It is of course important for supporting cooperative work that the perspectives maintain at least a partial overlap of their contents in order to reach successful mutual understanding and coordination. The underlying subjective opinions must be intertwined to establish intersubjective understanding [9, 25].

\section{Negotiation}

The concept of computer-mediated negotiation addresses the problem of making changes to a system design or an information repository when the changes may conflict with the interests of others. Such a change must first be proposed by someone. The same software that is used to prepare and propose the change should also inform the people affected and help them to respond to the proposal. According to Herrmann [10], the following options for voting and discussion should be offered: Accept, reject or modify the proposal. Furthermore, the proposal can be accepted until revoked or the computer-supported negotiation process can be interrupted in order to discuss the matter face-to-face, through telephone inquiry or in other ways of more direct communication. Each of the above options can be accompanied by commenting on the choice.

This concept of negotiation was originally developed within the context of software design for situations in which two users of a computer system discuss whether a system feature should be implemented or not. The approach was intended to support "controllability" and "suitability for individualization" (cf. ISO 9234, Part 10) for groupware. Such negotiation can take place in multiple cycles of a proposer and a responder reacting to each other. Negotiation rules must be established to define how many negotiation cycles can take place, how much time is allowed to pass before a decision must be reached, what happens when a time limit is reached, etc. The goal of this negotiation mechanism is to get through routine cases of agreement, abstention, or simple modifications of proposals as quickly as possible in order to determine efficiently which proposals require a more intensive communication process. This provides a common starting point from which cooperation can proceed.

A disadvantage of this negotiation mechanism is that it was designed for just two people. If applied to several participants, the time 
period for arriving at a common starting point stretches out too much. The original negotiation concept assumed that a modified item would not be worked on further until the negotiation process was complete. This might make sense in the case of a change of software system functionality, but it seems unduly restrictive for modifications of information and analysis. By contrast, the approach of intertwining multiple perspectives into a common one has the advantage that participants can continue to work in their own perspective while awaiting the results of negotiations. This allows the negotiation mechanism to be extended from pairs of participants to small groups.

\section{RELATED WORK}

This work builds on ideas from a variety of CSCW approaches.

\section{Hypertext and Hypermedia.}

Hypertext and hypermedia structures provide an important mechanism for supporting cooperative work with shared materials. To some extent, this is now provided by the Web itself, although many hypertext mechanisms have been explored that go beyond the Web's simple model [2]. The perspectives mechanism of Stahl [23] is a hypermedia implementation, based on a node and link structure; relationships among contents in different perspectives are defined by links. Internal manipulation of nodes and links allows multiple perspectives to share large information sources without unnecessary duplication. The use of "virtual copying" or "delta storage" is well-known in system software [7], but was not previously used in CSCW hypermedia systems. We have chosen to implement our own hypermedia substrate - rather then use something like Lotus Notes - for reasons of granularity, control, and speed.

\section{Context Mechanisms}

The importance of perspectives in cooperative work has been recognized at a theoretical level by Boland [5] and others, primarily based on the hermeneutic tradition in philosophy: Heidegger and 
Gadamer (see [23]). The application of virtual copying to perspectives on data was explored at Xerox PARC [4], but abandoned as too complicated for users at that time. A related mechanism of transclusion was proposed by Nelson [16] for hypertext. McCall applied a similar approach for organizing hypertext information by domain and version in Phidias [15]. Stahl [23] extended McCall's approach in Hermes, implementing a hypertext version of virtual copying in a productivity tool for professional design teams. He subsequently adapted this mechanism in CIE, a cooperative information environment for supporting peer group management of ISO 9000 documentation [22].

\section{Computer Supported Collaborative Learning}

A number of software systems have been developed to support collaboration of research teams in schools; CSCL [13] has become an important new research direction within CSCW. CSILE [19], for instance, is a threaded discussion system customized to scaffold classroom research. Systems like CoVis [17] and CaMILLE [21] also provide a shared workspace or notebook area for collecting research results. Rather than supporting negotiation through the system, they rely on face-to-face interactions to make choices about what materials get entered into the team repository. The prototypes of WebGuide are intended to demonstrate how current CSCL systems - which lack explicit representations of perspectives - can be enhanced.

\section{Organizational Memories}

By organizational memories we mean an approach to building a structured digital library of various forms of information that can be shared by community members through computer supported collaboration and communication mechanisms [1, 14]. Intertwined perspectives can help to structure an organizational memory. For instance, when a group of community members undertakes a new project they can create a new perspective on the memory and negotiate which items from existing perspectives should be included for use in the new project. 


\section{Collaborative Filtering}

Collaborative filtering (e.g. GroupLens, [18]) is typical of approaches that try to automate the construction of perspectives. It displays available information in accordance with individual or team preferences. Statistical analyses are used to automatically determine which members of a group are interested in similar topics. Items of information that are of interest to one member are then sent to other group members with similar interests. Rather than relying entirely on automated mechanisms, WebGuide allows active selection or modification of information by users.

\section{Conflict Management}

The above approaches lack any computer supported negotiation mechanisms. Wulf [27] proposed the support of negotiation and developed it for conflict management in groupware. Wulf focuses on negotiation between two persons and he distinguishes various ways in which a groupware user can avoid or reduce the effects of another user's actions. However, we believe that it should always be possible for users to react to each other, at least by commenting. Ideally, these reactions back and forth should take place with support from the same system that presents the content under discussion.

\section{Decision and Meeting Support}

The clearest parallels to computer-supported negotiation are decision support and meeting support systems. In these systems, one can respond to proposals from others by extending them with one's own proposals or amendments. One can also annotate the proposals. In more elaborate systems, such as those derived from Argnoter [24], annotations can be classified as pro or con the argument. Several systems keep track of votes for or against a proposal [6]. Sen, et al. [20] describe an application of this for meeting scheduling. Our negotiation mechanism emphasizes the possibility of continuing the work on a perspective before the decision process is completed. 
Due to space limitations, we cannot compare our work with approaches which are focussed on synchronous collaboration and WYSIWIS problems or deal with merging and access mechanisms in the field of joint editing. As pointed out above, these approaches are related to another type of problem where the shared information is relatively limited and can be described by a small set of document versions.

\section{THE WEBGUIDE DESIGN}

This section recounts the motivation and history of the design of our integration of perspective and negotiation $\mathrm{CSCW}$ mechanisms. It discusses a context in which future researchers are being taught how to engage in cooperative work and how to use computer technologies to support their work.

\section{Supporting Cooperative Student Web Research}

In summer 1997 we decided to apply our vision of intertwining perspectives and negotiation to a situation in middle school $\left(6^{\text {th }}\right.$ grade, 12 year olds) classrooms we work with. The immediate presenting problem was that students could not keep track of Web site URLs they found during their Web research. The larger issue was how to support team projects. The more we discussed computer support for cooperative student Web research, the more complicated and detailed the issues became.

To facilitate our own collaboration we adopted two representations: (1) the design of a detailed user interface using HTML and (2) a formal model of the software procedures, data elements, and context of use. You will see both representations below. The result of our collaboration is (1) an interface design for WebGuide, a Web-based prototype that integrates perspective and negotiation mechanisms to support collaborative learning, and (2) a model of such a system in use. To make our design concrete, we focused on a project-based curriculum [3] on ancient civilizations of Latin America used at the school. The example of this student research project is well suited to illustrate the level of complexity that our approach can and must handle. 
WebGuide was first conceived of as a glorified Web bookmark manager [12] and electronic notebook application [26], enhanced with perspective and negotiation mechanisms as described below. Students can conduct Web searches, collect, annotate, categorize, and organize bookmarks for sites they like. They can summarize or excerpt the Web page contents (there is no need to copy the full contents because it is already available through the active bookmarks). Students are encouraged to use the facilities of WebGuide to make the results of their research more self-explanatory for themselves and their team mates by defining a hierarchy of headings or categories, arranging bookmarks under these, and adding concise summaries of the content or importance of the bookmarked sites.

Figure 1 shows a view of a student's personal perspective in WebGuide. There are three topics visible in this view. Within each topic are short subheadings or comments, as well as Web bookmarks and search queries. At the bottom is access to search engines.

\section{Varieties of Information}

In compiling a list of requirements for WebGuide, we focused on how computer support can help structure the merging of individual results. Such support should begin early and continue throughout the research process. It should scaffold and facilitate the decision-making process so that students can learn how to build consensus. WebGuide combines displays of individual work with the emerging group view. Note that the topic on Aztec Religion in Figure 1 has been proposed by another student to be part of the team perspective. Kay has made a virtual copy of Que's topic so she can keep track of his work related to her topic. The third topic is an idea that Kay is preparing to work on herself. Within her electronic workspace she inherits information from other perspectives along with her own work.

Each student should be able to view the work of other team members as they work on it, not just when it is submitted to the team. Students should be able to adopt individual items from the work of other students into their own perspective, in order to start the collaboration and integration process. This can be done with the comparison perspective (see Figure 2). From early on, they should be able to make proposals for moving specific items from their personal 


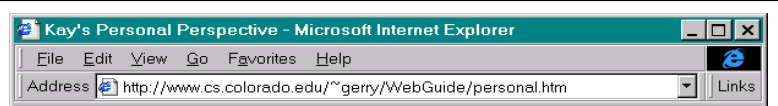

Aztec Religion Iproposed by Beal

SUMMARY TITLE: What role did religion play in the

Aztec social structure?

SUMMARY: How were science and religion

related duing the history of the Aztecs?

WEB : World Cultures

EXCITE: The Aztec rite of human sacrifice

WEB: Social Organization

Founding Mexico City [Que's perspective]

SUMMARY TITLE: What is the myth of the eagle

associated with the founding of Mexico City?

WEB: Aztec History \& Culture

\section{Live Sacrifice [Kay's perspective]}

SUMMARY TITLE: How widespread was live sacrifice

and why was it done?

WEB: The Aztecs: A Tradition of Religious Human Sacrifice

\section{Search Engines}

Altavista

Excite

e] $\quad$ E Internetzone

Figure 1. Part of Kay's personal perspective. perspective (or from the perspective of another) into the team perspective, which will eventually represent their team product, the integration of all their work.

The Web pages of a student's personal perspective should not only contain live link bookmarks and search queries, but also categories, comments, notes, and summaries authored by the student. All these elements are representations of what we have abstractly called "items" of information.

Comments can optionally be attached to any information item. Every item is tagged with the name of the person who created or last modified it. Items are also labeled with perspective information and time stamps.

The requirement that items of information can be copied, modified, and rearranged presupposes that information can be collected and presented in small pieces. This is also necessary for negotiating which pieces should be accepted, modified, or deleted.

In addition to bookmarks, the WebGuide page can contain Web search queries for finding current sites on a given topic. WebGuide is designed to help students learn to do Web research, and the sharing of successful query formulations is important for that. WebGuide pages are structured by topic headings or categories for organizing the 
bookmarks and queries. These categories can initially be created without any bookmarks or queries as preparation for looking for relevant information, as Kay has done for the topics of Mexico City and Live Sacrifice (in Figure 1) that she intends to research. The categories are structured hierarchically to create a tree of information.

Because of the hierarchical nature of items, something that appears as a unit of information that can be proposed for negotiation may actually consist of many parts, some of which appear differently in

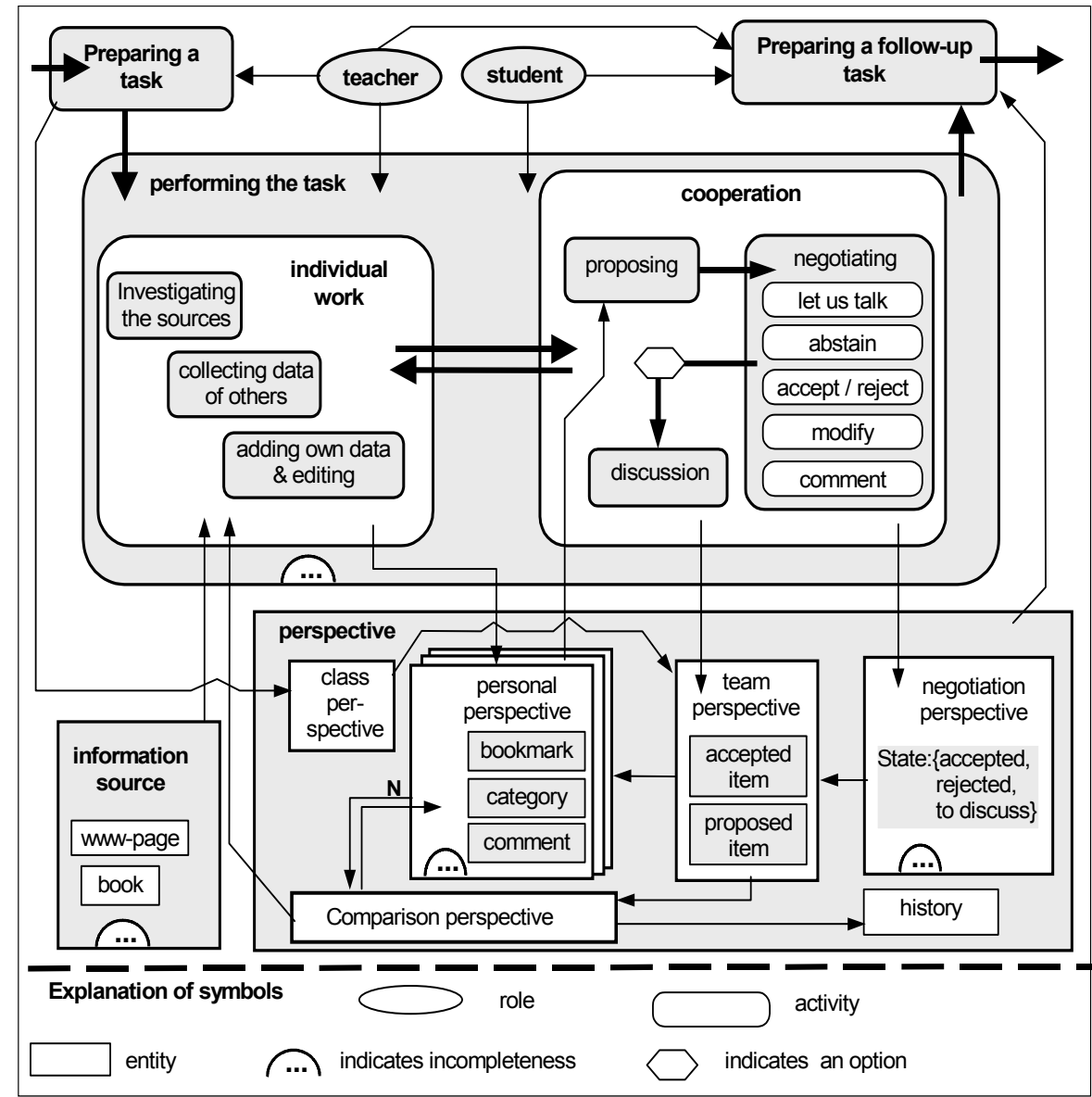

Figure 2. Model of the task performance and perspectives. 
different students' perspectives. The possibility of information items having a complex but hidden internal structure is required for the intertwining of perspectives and negotiation.

\section{Types of Perspectives}

WebGuide provides six types of perspectives to help students compile their individual and joint research (Figure 2 shows how they are related to each other and to the activities):

1. The student's personal perspective is their private work space. It inherits a view of everything in the team perspective. Thus, it displays the owner's own work within the context of items proposed or negotiated by the team and class - as modified by the student. Students can each modify (add, edit, delete, rearrange, link) their virtual copies of team items in their personal perspectives. They can also create completely new material there.

2. The team perspective contains both items that have already been accepted by the team and items that are currently proposed for negotiation (like the Aztec religion topic in Figure 1). This perspective is pivotal. It includes accepted and proposed items. It gradually collects the products of the team efforts.

3. The class perspective is created by the teacher to start each team off with some initial bookmarks and suggested topics. It typically presents a structure for classroom activities and provides the space used to instantiate the goal of collecting the products of cooperative intellectual work. It has the organizational function of structuring the team perspective.

4. The comparison perspective combines all the personal perspectives of team members and the team perspective, so that anyone can compare all the work that is going on. It inherits from the personal, team, and class perspectives. Students can go here to get ideas and copy items into their own personal perspective or propose items for the team perspective.

5. The negotiation perspective contains all the information related to the current status of negotiation on the items 
proposed for the team perspective. It inherits proposed items from the team perspective. When they are approved or rejected at the end of negotiation, their status in the team perspective changes. It has the organizational function of making the process of negotiation more comprehensible.

6. The history perspective is an archive of all information that has been entered in WebGuide. It is primarily for the teacher (or researchers), but can also be used by students to retrieve previous versions of items. It inherits from the comparison perspective, that contains information from all the other perspectives.

Of course, there is not really such a multiplicity of information in the central database. The perspectives mechanism merely displays the information differently in the different perspectival Web pages, in accordance with the relations of inheritance. Organizational information as well as content are represented in a consistent way by using the perspectives mechanism.

\section{Practices and Perspectives}

To design software for collaborative learning in schools means to design curriculum and classroom process as well. Computer support has to be matched with appropriate content on the Web and with a constructivist pedagogy [19]. The design of the WebGuide interface and the perspective and negotiation mechanisms is accompanied by the design of informative Web pages and of a use scenario.

Figure 2 shows a model of the process involving the teacher, the students, and tasks using WebGuide. It shows the relation of individual to cooperative work and the mediating roles of the perspective and negotiation processes.

The model in Figure 2 represents the process flows. Students research using sources available to them: the Web, books, encyclopedia, CD-ROM, discussions, or other sources. Students can review the contents of the class perspective, their team perspective, and the personal perspectives of their team mates. All of these contents are collected in the comparison perspective, where they are labeled by their perspective of origin. Students extract from the research those items which are of interest to them. Then they organize and develop the data 
they have collected by categorizing, summarizing, labeling, and annotating. The three stages of investigating, collecting, and editing can be repeated as many times as necessary.

To support these steps of the work, WebGuide provides a menu of functionality for each information item. The following menu options are included: show/hide detail, Add a new item, Move this item, Edit this item's text, Delete item, Copy to my perspective, Propose to team, and Negotiate this item.

The class project ends with each team producing an organized Web site about one of the civilizations. These Web sites can be used by members of the other teams to learn about the civilizations that they did not personally research. The sites can also provide a basis for additional class projects, like narrative reports and physical displays. Finally, this year's research products can be used to create next year's class perspective starting point, so new researchers can pick up where the previous generation left off - within a World Wide Web that will have evolved substantially in the meantime.

\section{Negotiation Procedures}

A student can make proposals for the team perspective from the Propose to team option within his or her personal perspective. This is how new items get introduced into the team perspective. A student can also propose an item from someone else's perspective by locating it in the comparison perspective. If she wishes to modify it, she can first copy it into her own perspective. If someone wishes to modify an item that is already in the team perspective, she must copy it into her own perspective, make the modifications there, and then propose the modified item.

It should be possible when proposing - just as with copying - to treat a set of related items in one step. It is important to be able to treat a set of proposed changes together. For example, if a student deletes a bookmark at one spot in order to replace it with a better, richer bookmark elsewhere, then the deletion and the replacement should both be proposed and negotiated together. Of course, students should be discouraged from grouping too many items together. 


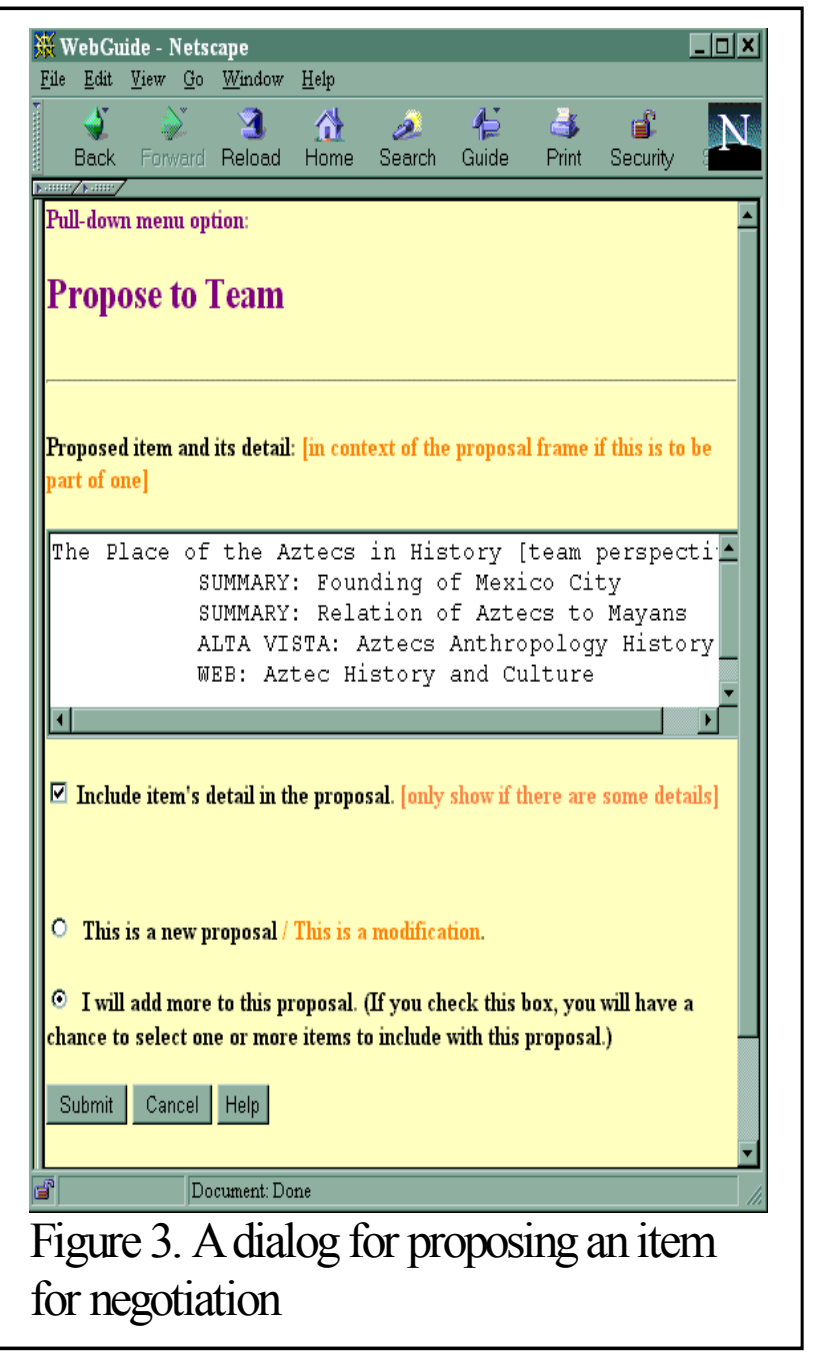

When a student selects the Propose to team menu option for an item, a dialog box opens (see Figure 3). The student can decide whether the new proposal item should be combined with a previous or future proposal. The proposer also sees a list of all the other students who will be involved in the negotiation of the item. The determination of who should be involved is a matter for installation settings that define a local negotiation policy. These settings are system parameters of WebGuide, so they can be easily varied by teachers or research user communities. 
For example, one might want to establish a rule that all new items must be negotiated by all team members - or alternatively that they do not require negotiation at all - while modified items require just those people to participate who either originally created the item or subsequently modified it. Another plausible rule would be to accept all annotations without negotiation.

As soon as an item is proposed, it appears in the negotiation perspective. Through perspective inheritance, it also appears in the

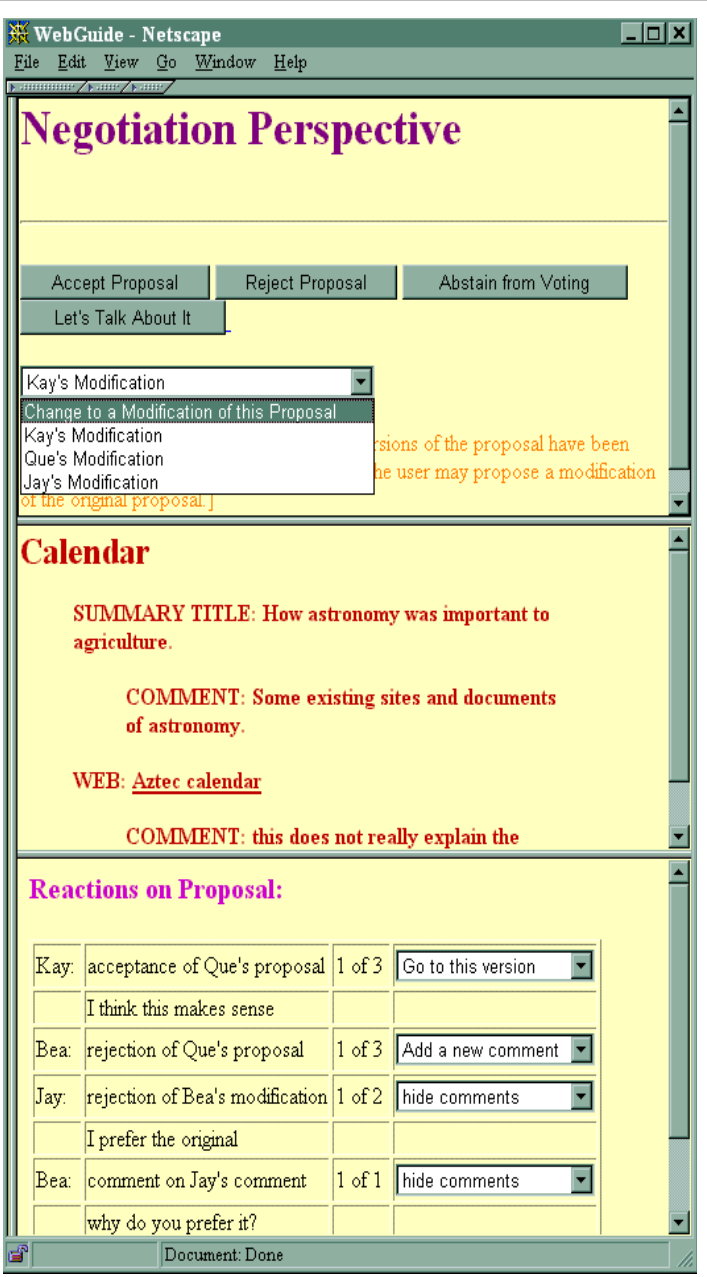

Figure 4. The Negotiation Perspective 
team perspective and in the personal perspective of all team members, labeled as Proposed by name-of-proposer. A student can select the Negotiate this item menu option for the item to switch to the negotiation perspective for that item.

There are three windows (see Figure 4). The top window includes buttons corresponding to the negotiation options: Accept, Reject, Abstain, and Let's talk. The second window displays the proposed item or items within the context they would have in the team perspective once accepted. The bottom window contains the results of negotiation decisions already made about the proposal and the commentary of team members concerning these decisions. No editing of the proposal is allowed in the negotiation or team perspective.

Several negotiation responses to the proposal are possible at this point. A negotiator can indicate that she abstains, that she does not care to participate in the negotiation. Alternatively, she could indicate with Let's talk that she would like to discuss the proposal face-to-face in the team. In the later case, the label on the proposed item changes to Proposed by name-of-proposer, Let's talk. In addition, an automatically maintained agenda of points for group discussion is extended to include this proposal.

Of course, the primary options are to Accept or Reject the proposal. It should be noted that a proposal can have been modified by other group members so that there may be several versions of the same proposal. If Accept is selected for one alternative, then all the others are assigned Reject and the negotiation is over for that student. If Reject is selected, then the next version of the proposal is displayed. When several versions are available, a student can either accept precisely one or reject them all.

After making a negotiation decision, a student should comment on the reasoning behind her response. All students who view the negotiation perspective after that can see her response with her comment. Although it may not be sensible in a negotiation situation involving several participants to allow cycles of responses to responses because the negotiation process would quickly become too confusing, WebGuide does allow students (and teachers) to comment on all actions, including comments on comments. This allows a simple kind of threaded discussion. Even after a student has completed her voting 
on a proposal she can comment on other people's choices or change her vote.

The procedure for amending a proposal is a bit involved. Once a student has rejected all the existing versions of a proposal, she can modify (see Figure 2) the proposal in her personal perspective and propose her amended version. This is how more than one version of a single proposal can become part of the negotiation perspective. Then the new version will be automatically integrated into the negotiation process of the original proposal. The label of the proposed item will be altered to read, Proposed by name-of-first-proposer amended by name-of-second-proposer. Students who have already voted will see this new label and can decide if they want to return to the negotiation perspective and reconsider their vote on this proposal. It might also make sense to have a more intrusive mechanism to alert people to newly proposed versions. The design decision to restrict modifications this way in the negotiation process results in a simplification of the process. To avoid confusion, it is only possible to edit the original proposal, not proposals that already have the label amended. While a proposal can be rejected by its original proposer when she prefers an alternative version, it cannot be recalled because that would create an asymmetry between the proposer and other participants.

The negotiation process for a proposal cannot exceed a time limit, determined by the negotiation policy parameters. At the end of the time period, the system determines whether the proposal or a modified version is accepted or rejected. Again, installation parameters determine what kind of majority is required: $2 / 3$ of those voting, majority of those eligible, simple majority, etc. If the results are indecisive, the proposal will be labeled proposed for talk and added to the discussion agenda. Then students will have to get together in the classroom and decide what to do about the proposal. When matters are decided in group meetings, someone with a special password can enter changes directly in the team perspective, shortcutting the computer-supported negotiation process. 


\section{WEBGUIDE IN PRACTICE}

\section{Cooperative Definition of Keywords for a Bibliographic Database}

The concept of intertwining perspectives and negotiation is a general one which can be tailored to fit many cooperative work domains. For instance, we have experimented with the negotiation procedures described above in a system for use by academic researchers who share a collaborative on-line bibliography. This system was implemented and used in our research center at the University of Dortmund. The system is based on WebGuide mechanisms and functions.

We started with a literature database that was created in 1988 for our research group. It originally contained about 500 entries. The literary references were classified according to their content using a set of about 50 keywords. The database quickly grew to about 3,000 entries indexed by 200 keywords. The quality of the system deteriorated with this growth: it accumulated duplicate and outdated entries, many entries were inadequately indexed, and the keywords became overlapping and outdated as well. A clear need for convergence could be empirically observed.

To address these problems, we created an experimental new system. Each member of the research group was given their own perspective on the database of entries and keywords; they are now responsible for maintaining the information they are interested in. Information they are interested in but do not want to maintain themselves they can access by virtual links to other perspectives. All literary references and keywords that one considers important for the team can be proposed for the team perspective and negotiated.

Consider the following use scenario: Andy browses the comparison perspective and finds an interesting keyword, $\mathrm{K}_{1}$, from Barbara. He makes a virtual copy of it in his personal perspective. Andy can now use the keyword to retrieve all entries that are classified with it. However, before Andy can use $\mathrm{K}_{1}$ himself to classify a new entry, he must make a physical copy of it $\left(\mathrm{K}_{1} \rightarrow \mathrm{K}_{2}\right)$. This will protect Barbara from being affected by Andy's classification activities. If Andy had continued to use a virtual copy of $\mathrm{K}_{1}$ then he would retrieve not only his own but also Barbara's classifications of $\mathrm{K}_{1}$ when he did a search 
for $\mathrm{K}_{1}$. Andy can also introduce a new keyword, $\mathrm{K}_{3}$, and propose it to his team if he thinks it is an important keyword. Even while his team is negotiating the acceptance of this keyword, Andy can already begin to classify references using $\mathrm{K}_{3}$. If and when $\mathrm{K}_{3}$ is accepted by the team, all the references that had been classified with $\mathrm{K}_{3}$ will be automatically proposed for acceptance in the team perspective for negotiation, one at a time.

This prototype system has been explored by a team of six researchers working cooperatively on various projects. Based on these trials, the following principles were proposed as preconditions for regular use of such a system:

- In order to reduce the complexity and the burden of excessive negotiation processes, negotiation should only take place when a new entry is proposed to the team, when the classification of an entry by a keyword is to be changed, or when a keyword itself is being altered. All other changes should simply be accepted automatically without negotiation.

- There should be system functionality to notify team members when a new keyword is introduced (even in a personal perspectives), when someone creates a virtual link to a keyword, and when someone makes a new proposal.

- Proposals make sense not only at the team perspective level; it is also useful for one team member to propose a new item to another team member.

- It should be possible to define sub-team perspectives to represent the interests of small research units and projects.

\section{Negotiating Environmental Perspectives}

We are now using an early implementation of WebGuide in a middle school classroom in Denver. (See Figure 5 for a screen image of this Java applet running on the Web). For the past five years, this class of students researched the environmental damage done to mountain streams by "acid mine drainage" from deserted gold mines in the Rocky Mountains above Denver. They actually solved the problem at the source of a stream coming into Boulder from the Gamble Gulch mine site. In 1998/99 they investigated the broader ramifications of their past successes, looking at the issue of acid mine drainage from various 


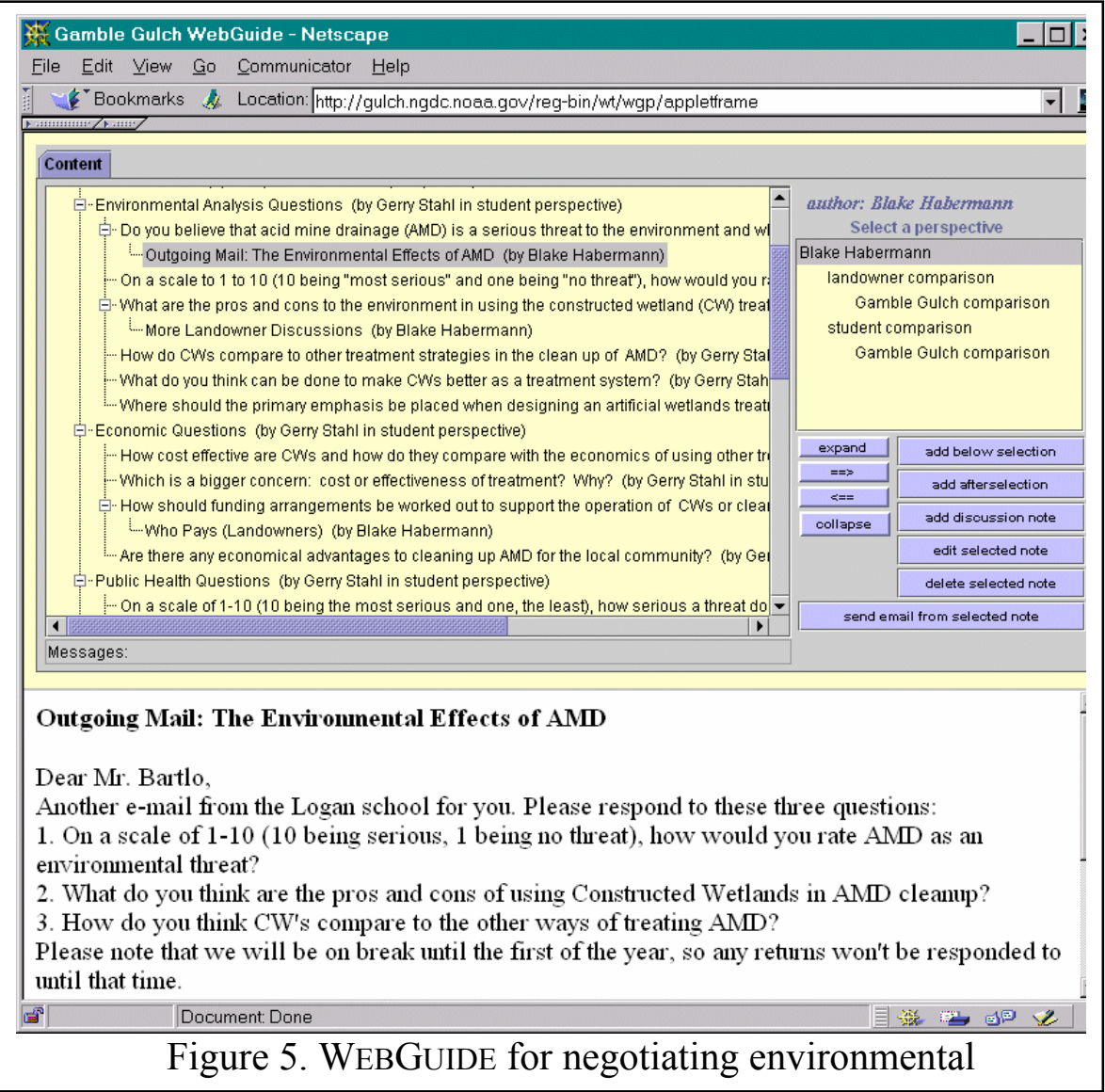

alternative perspectives. They interviewed adult mentors to get opinions from specific perspectives: environmental, governmental, mine owners, local residents, scientists, etc.

WebGuide serves as the medium through which the students cooperatively research these issues with their mentors and with each other. Each student and mentor has their personal perspective, and these perspectives inherit from the content-based perspectives (environmental protection, governmental regulation, etc.) depending upon which intellectual perspective they are working on constructing. Even email interactions happen through WebGuide and are retained as notes in its perspectives. The goal of the year-long course is not only to negotiate within teams to construct the various positions, but also to negotiate among the positions to reach consensus or clarify differences. 
As an initial field testing of the WebGuide system, this trial has resulted in valuable experience in the practicalities of deploying such a sophisticated program to young students over the Web. The students are enthusiastic users of the system and offer many ideas for improvements to the interface and the functionality. Consequently, WebGuide is benefiting from rapid cycles of participatory design. One main result is that the possibilities of achieving convergence of the contributions have to be improved. It proved to be a serious lack that this early version of WebGuide did not provide support for negotiation. The ideas of the students diverged within WebGuide and the teacher had to bring them together and build a consensus during face-to-face class discussions.

\section{Constructing Perspectives on CSCL}

An interdisciplinary graduate seminar on computer mediation of collaborative learning is also using WebGuide in several ways during 1999:

- As a communication medium for their internal cooperation.

- As an example CSCL system to analyze.

- As an electronic workspace for them to construct their individual and shared ideas.

This version of WebGuide stresses the use of perspectives for structuring collaborative efforts to construct shared knowledge.

Students in the class can form sub-groups either within or across their different disciplines. They develop ideas in their personal perspectives and then debate these ideas in the various comparison perspectives of their sub-groups. Here, it is an important result that the comparison perspectives are directly used to conduct a kind of prenegotiation process. This helps to determine which notes are promoted to the class or team perspective.

A major hypothesis being explored by the course is that the use of a shared persistent information space can support more complex discussions than ephemeral face-to-face conversations. 


\section{FUTURE WORK}

WebGuide is currently under intensive development and testing. Now that we have initial demos of our concept, we are engaging in participatory design with teachers, students, and research groups to refine the approach. Initial evaluation of some of its concepts will be conducted in middle school, high school, college and graduate classrooms in Boulder, Colorado. We will investigate how different features are used in practice. For instance: Do students move fluidly and effectively among the different perspectives? To what extent do students group related proposals together? How much do students comment on their negotiation decisions or on those of others? Can students handle the process of modifying proposals? We will also explore different negotiation policy parameters: What happens to proposals that just one or two students slate for group discussion? What time limits, voting methods, negotiation participation rules are meaningful and effective?

In parallel with the testing of WebGuide in Colorado, the system will be used in courses at the University of Dortmund. In these courses, future teachers in various disciplines will be trained in the fundamentals of computer technology and its use in the classroom. These teachers-in-training will gain both theoretical knowledge and practical experience through their work with WebGuide.

The system for cooperative use of the bibliographic database described above will be developed further and used on a more regular basis. Thereby, we will explore whether the concepts there can also be applied to support organizational memories. As more of the WebGuide functionality is implemented and deployed in a variety of CSCW and CSCL applications, we will see how effective the intertwining of perspectives and negotiation can be.

\section{ACKNOWLEDGEMENTS}

The research reported here was begun during a six month visit by Herrmann to Boulder in 1997. It is being continued by Herrmann and his students at Dortmund, Stahl and his students, Ted Habermann and his group at NOAA, Dan Kowal and his middle school students, and the researchers, teachers, and students in the "Articulate Learners" 
project. The work reported here is supported in part by grants from NSF IRI-9711951, the McDonnell Foundation, and NSF EAR9870934.

\section{REFERENCES}

1. Ackerman, M. S. (1994) Augmenting the organizational memory: A field study of Answer Garden. In: Proceedings of CSCW '94, ACM Press, 243-252.

2. Bieber, M., Vitali, F., Ashman, H., Balasubramanian, V., OinasKukkonen, H. (1997) Fourth generation hypermedia: Some missing links for the World Wide Web. International Journal of HumanComputer Studies. Special issue on HCI \& the Web.

3. Blumenfeld, P., Soloway, E., Marx, R., Krajcik, J., Guzdial, M., Palincsar, A. (1991) Motivating project-based learning: Sustaining the doing, supporting the learning. Educational Psychologist. 26, 369-398.

4. Bobrow, D. \& Goldstein, I. (1980) An experimental descriptionbased programming environment: Four reports. Technical Report CSL-81-3. Palo Alto, CA: Xerox Palo Alto Research Center.

5. Boland, R. J. \& Tenkasi, R. V. (1995) Perspective making and perspective taking in communities of knowing. Organization Science. 6, 4, 350-372.

6. Ephrati, E., Zlotkin, G., Rosenschein, J. (1994) Meet your destiny: A non-manipulable meeting scheduler. In: Proceedings of $\mathrm{CSCW}$ '94. ACM Press. 359-371.

7. Fitzgerald F., Rashid R. (1986) The integration of virtual memory management and interprocess communication in accent. $A C M$ Transactions on Computer Systems, 4, 2, 147-166.

8. Floyd, C. (1992) Software development and reality construction. In: Floyd, C., Züllinghoven, H., Budde, R., Keil-Slawik, R.. Software Development and Reality Construction Springer-Verlag. 86-100.

9. Habermas, J. (1981) Theorie des kommunikativen Handelns. Band 1. Handlungsrationalität und gesellschaftliche Rationalisierung. Suhrkamp Verlag. 
10. Herrmann, T. (1995) Workflow management systems: Ensuring organizational flexibility by possibilities of adaptation and negotiation. In: Proceedings of COOCS'95. Conference on Organizational Computing Systems. ACM Press, 83 - 95.

11. Herrmann, Th., Wulf,V., Hartmann, A. (1996) Requirements for a Human-centered Design of Groupware; in: Shapiro, D.; Tauber, M.; Traunmüller, R. (eds):Design of Computer Supported Cooperative Work and Groupware Systems, Elsevier, Amsterdam, S. 77 - 100.

12. Keller, R., Wolfe, S., Chen, J., Rabinowitz, J., Mathe, N. (1997) A bookmarking service for organizing and sharing URLs. In: Computer Networks and ISDN Systems. 29, 1103-1114.

13. Koschmann, T. (ed.) (1996) CSCL: Theory and Practice. Lawrence Erlbaum Associates.

14. Lindstaedt, S., Schneider, K. (1997) Bridging the gap between faceto-face communication and long-term collaboration. In: Proceedings of the International ACM SigGroup Conference on Supporting Group Work. The Integration Challenge. ACM Press. 331-340.

15. McCall, R., Bennett, P., d'Oronzio, P., Ostwald, J., Shipman, F., Wallace, N. (1990) Phidias: Integrating CAD graphics into dynamic hypertext. In: Proceedings of ECHT '90. 152-165.

16. Nelson, T. H. (1981) Literary Machines. Mindful Press.

17. Pea, R. (1993) The collaborative visualization project. Comm. ACM. 36, 5, 60-63.

18. Resnick, P., Iacovou, N., Suchak, M., Bergstrom, P. (1996) GroupLens: An open architecture for collaborative filtering of netnews. In: Proceedings of $C S C W^{\prime}$ '94. ACM Press. 175 -186.

19. Scardemalia, M. \& Bereiter, C. (1991) Higher levels of agency for children in knowledge building: A challenge for the design of new knowledge media. Journal of the Learning Sciences, 1, 37-68.

20. Sen, S., Haynes, T., Arora, N. (1997) Satisfying user preferences while negotiating meetings. Int. J. Human-Computer Studies. 407427. 
21. Soloway, E., Guzdial, M., Hay, K. (1994) Learner-centered design: The next challenge for HCI. ACM Interactions. 1, 2, 36-48.

22. Stahl, G. (1996) Personalizing the Web. Available at http://www.cs.colorado.edu/ gerry/publications //techreports/www6/PAPER82.html.

23. Stahl, G. (1993) Interpretation in Design: The Problem of Tacit and Explicit Understanding in Computer Support of Cooperative Design, Chapter 9. Unpublished Ph.D. Dissertation. available at http://www.cs.colorado.edu/ gerry/publications/ dissertations/Ch09.html.

24. Stefik, M., Foster, D., Bobrow, D.G., Kahn, K., Lanning, S., Suchman, L. (1988) Beyond the chalkboard: Computer support for collaboration and problem solving in meetings. In: Greif, I. (Ed.) Computer-Supported Cooperative Work. 335-366.

25. Tomasello, M., Kruger, A.C., Ratner, H. (1993) Cultural learning. Behavioral and Brain Sciences. 495-552.

26. Torrance, M. (1995) Active notebook: A personal and group productivity tool for managing information. In: Proc. AAAI Fall Symposium on Artificial Intelligence in Knowledge Navigation and Retrieval. 131-135.

27. Wulf, V.(1995): Negotiability: A Metafunction to Handle Access to Data in Groupware; in: Behaviour \& Information Technology, Vol. 14, No. 3, ,S. 143 - 151. 